\title{
A Study on the Relationship Between Red Memorial Landscape Perception, Collective Memory, and Identity_-Take the Martyrs Monument as An Example
}

\author{
Huimin $\mathrm{Xu}^{1}$, Shizhu Jin ${ }^{1,2}$ \\ ${ }^{1}$ College of Geography and Ocean Sciences, Yanbian University, Park Road 977, Yanji, China \\ xuhuimin1023@163.com \\ ${ }^{2}$ College of Integration Science, Yanbian University, Park Road 977, Yanji, China \\ jinsz@ybu.edu.cn
}

\begin{abstract}
Landscape Perception, Memory and Identity are hot topics in landscape research and emotional research in new cultural geography. Although the relationship between the three is supported by a small number of empirical cases, there is a lack of corresponding quantitative research. In this context, the article introduces the commonly used testing methods of intermediary effects in psychology and economics to geography, takes red landscape perception as an independent variable, collective memory as an intermediary variable, and identification as a dependent variable. SPSS 22.0 and AMOS 24.0 are used to analyze the relationship between "landscape perception-collective memory-identity". The results of the research are as follows: 1) On the whole, residents have a higher perception of the red cultural landscape, but the recognition of image appearance items varies.2) Landscape perception variables can predict collective memory variables. 3) Collective memory positively affects residents' sense of identity. 4) Landscape perception can not only directly act on identity, but also have a positive effect on residents' sense of identity through collective memory of residents, and part of the mediating effect played by collective memory has been verified.
\end{abstract}

Keywords: Red memorial landscape, Landscape perception, Collective memory, Identity, Mediation effect.

\section{Introduction}

Since the 18th National Congress of the Communist Party of China, Chinese president $\mathrm{Xi}$ has repeatedly set foot on the red holy land to worship the martyrs, review the history of the Communist Party of China, and emphasize the significance of the red culture. Theme activities such as history exhibitions of Communist Party of China, red stories talking, and red tourism with red culture as the core are being carried out all over the country. Red culture is the material and spiritual wealth accumulated by the people in a series of great practices of defending the motherland under the leadership of the party since 1921. The martyrs monument is a representative of the red cultural landscape. As one of the means to strengthen local and national power, the red cultural landscape plays an important role in guiding residents to improve their ideological awareness, shaping collective memory, and enhancing identity. The significance of the red cultural landscape is worthy of study by scholars.

In terms of research content, with the theme of Landscape Perception, Chinese geographers mostly study the Landscape Perception from the perspective of tourists, and some scholars use the local cultural landscape as the theme to explore the status quo of residents' perception (Yang, et al., 2014) and the changes of residents' perception of the landscape under the influence of tourism (Yin, et al., 2021). Traditional Rural Landscapes, Calligraphy Landscapes, and Cooking Culture Landscapes are the main research topics, and the perception of red cultural landscapes such as martyrs monuments is still on the "edge" of perception research (Liu, 2019). The research of Landscape Perception in foreign countries originated earlier, and the subject matter is more diversified (Wheeler, 2014). A large number of tourism geography articles with tourists' Collective Memory as the content reflect the domestic geography's research preference for collective memory (Qian, 2020). Not only is it limited to the dimension of tourists, there are also abundant foreign researches on Collective Memory from the perspective of residents (Alice, 2010). Since Identity introduced into geography, it has always been studied by geographers at home and abroad, especially the results of Place Identity are the most significant (Zhu and Liu, 2011). In addition to a few qualitative studies on the relationship between the three (Liu and Guo, 2021), most Chinese geographers has placed the research focus on the relationship between the two variables: cultural landscape and collective memory (Kong and Zhuo, 2017), landscape and identity (Qi and Tang, 2020), memory and identity (Sun and Zhou, 2015). European and American articles on the relationship between the three are relatively substantial, and most articles aim to highlight: the memory that originated from the place has the role of shaping identity (Drozdzewski, 2014).

In relation to research methods, the Analyses of Mediating Effects is a classic method in psychology and economics, and is often used to study the relationship between variables (Hur, et al., 2014). Some geographers use this method to carry out a certain amount of academic research. However, it has not been a popular method used by the geographers ( $\mathrm{Xu}$ and $\mathrm{Zhou,}$ 2020).

In the selection of study area, Yanbian Korean Autonomous Prefecture located in the southeast of Jilin Province, China. And it was the center of fighting against Japanese imperialism activities in Northeast Asia, and $90 \%$ of its townships are Old Revolutionary Bases Area. Regardless of the province, the 
Northeast region, and the whole country as well as Northeast Asia, its red cultural accumulation and red resource reserves in this area are outstanding. Yanbian city should be a typical place for red landscape research, but it has been ignored by scholars at home and abroad.

To sum up, in order to actively respond to the call of president $\mathrm{Xi}$ to "Make good use of red resources and inherit the red genes", to fill the gap in the quantitative study of the relationship between the three in the new cultural geography. The article uses Yanbian city as study area, martyrs monument as a typical landscape, and Yanbian city residents as a survey group. Quantitative methods are used to try to summarize the characteristics of local residents' perception of martyrs monument, and to sort out the relationship between Landscape Perception, Collective Memory and Identity. This paper is expected to enrich the existing theoretical results, provide scientific and detailed theoretical references for follow-up research, and provide assistance in practice for the protection and development of the red cultural landscape.

\section{Literature Review and Research Hypothesis}

\subsection{Literature Review}

In 1885, Hamerton gave the Landscape a modern meaning that is the entire surface that can be seen in a particular place (as cited in Tang, 2000, p. 70-79). In the 1920s, Sauer Carl Ortwin, the founder of the Cultural Landscape School, defined Landscape as a region composed of significant connections between nature and culture, and called on human geographers to improve their understanding of culture in the landscape. The Cultural Landscape that is various forms of human activities attached to the natural landscape (De Blij, 1986). The Red Cultural Landscape refers to the revolutionary base areas, conference venues, war remnants etc. that have been experienced and constructed after the founding of the Communist Party of China (Yang, 2013). The Revolutionary Martyrs Memorial Building is one of the manifestations of the red cultural landscape. Measures for the Management and Protection of the Revolutionary Martyrs Memorial Building gives a clear concept "The Revolutionary Martyrs Memorial Building is a martyrs cemetery, memorial hall, monument pavilion and other buildings built for revolutionary martyrs". The Revolutionary Martyrs Monument is a monument facility specially built for revolutionary martyrs. Based on Psychology, the Perception of the Red Cultural Landscape can be regarded as an individual's cognition and feelings of the red cultural landscape with his/her own understanding.

Collective Memory was first proposed by the sociologist Maurice Halbwachs in The Social Structure of Memory in 1925, He described "The members of a specific social group share the process and results of the past" (Guo, 2002). Any society organizations or groups, such as families, countries, nationalities, etc. have their corresponding collective memories to condense this group of people (Li, et al., 2010) Among them, the abstract feature (spiritual) in Collective Memory is particularly important. Some sociologists regard Collective Memory as a process of social construction and discuss the mechanisms that influence the formation of collective memory (Li, 2009). Constructivism reminds us that in addition to paying attention to the influence of personal background and preference factors on memory, we should also pay attention to the role of environmental (landscape) clues in the construction and maintenance of Collective Memory.

In the 1950s, world entered a period of rapid development and intensified population mobility, many people experienced the problem of identity, and identity attracted attention. Sigmund Freud believes that Identification is actually a process of approaching and approaching human self to the ideas and values of others, emphasizing the instinct of human beings in the identification process. The American psychoanalyst Erikson revised the above statement and believed that Identity is actually a definition of the relationship between Us/Others, and Identity indicates the result of an individual's evaluation of the self and its relationship with society or others, he endowed Identity with a new connotation (after people examine the individual, they rationally separate the Us from the Other), and Identity (including Sense of Identity and Behavior of Identity) has become the interests of researchers in disciplines such as Sociology, Sociology, Anthropology, and Geography, as well as concepts and research papers related to Identity emerge in endlessly.

In 1983, environmental psychologist Pros-Hansky introduced the concept of Identity into Environmental Psychology, and defined Place Identity as the process by which individuals or groups interact with the place to achieve socialization. This special socialization includes emotions and perceptions. Through this process, individuals and groups define themselves as members of a certain place (Stedman, et al., 2004). Ethnic Identity includes a sense of belonging to the nation, a positive ethnic attitude, and active participation in ethnic social activities and cultural practices (Phinney, 1990). There is still no unified concept of National Identity. We quote the concept of National Identity proposed by Du (2014), which refers to the recognition by members of a country of the country's historical and cultural traditions, national sovereignty, political path, political opinions, and moral values.

\subsection{Research Hypothesis}

The meaning of a symbol is far more than the object itself, but its content, which is a cultural unit (Zhang, 2014). The significance of the martyrs monument is far beyond the visual experience that its magnificent and beautiful appearance brings to people. More importantly, it records the story of martyrs who did not care for themselves and defended the country during the war. It collects the indomitable and lofty spirit and the admiration of the local people for the martyrs. Symbols such as landscapes, rituals, and festivals connect individuals/groups and places. People's identification with these symbols is the most obvious sign of the formation of local identity. To some extent, the landscape symbol not only reflects the development process of the nation, but also the summary of the long history of the nation, showing the spirit and characteristics of the nation (Zhang, 2014). The national history and national spirit condensed by landscape symbols have played an important role in the process of cultivating personal national identity. The historical symbols are beneficial to build a sense of belonging for residents/tourists, and the country and local governments also try to use 
historical tracks, preserve and create environmental elements, wonders and parades, arts and crafts, as well as museums and monuments, in order to maintain this identification (Cloke, 2006).

The red memorial landscape perception has an obvious effect on local identity, ethnical identity, and national identity. Based on the above analysis, the following hypotheses are put forward (Figure 1):

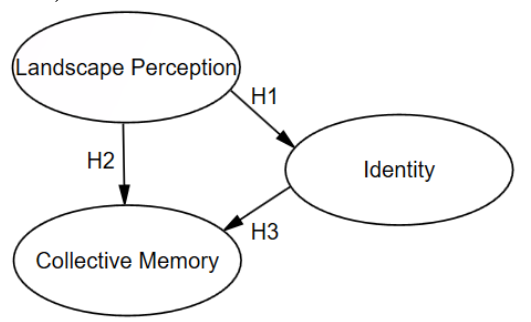

Figure 1: Hypothetical path diagram

H1: Landscape perception has a positive impact on residents' sense of identity.

Compared with individuals, the memory of a group depends more on symbols. Things with symbolic significance become important due to the description of historical records and become a symbol of people's collective memory. Without such symbols, it is difficult for a nation to make its own. Collective memory is passed on from generation to generation (Li, 2001). Red cultural landscapes, such as battle sites, martyrs' cemeteries (tombs), museums, and monuments, serve as the carriers of red memories, and undertake the functions of trauma narrative and memory shaping. Therefore, the landscape is an important carrier of collective memory. The perception of the landscape is crucial to the formation, arousal and maintenance of the collective memory of residents, so the following hypotheses are proposed:

H2: Landscape perception has a positive effect on collective memory.

The retention of memory makes the group characteristics form the basis of a group's collective consciousness. When the collective memory is evoked, the members of the group have a common identity with its past. Social groups can maintain their common identity for a long time through collective memory. Therefore, collective memory is not only a prerequisite for group identity, collective memory is also conducive to a certain social group to maintain its sense of identity. Based on this, the following hypotheses are proposed:

H3: Collective memory has a positive effect on residents' sense of identity.

Landscape, memory and identity are closely related. The red cultural landscape with narrative function is interpreted by residents personally, prompting them to construct their feelings and cognition of symbols. The "hidden" perception evokes the collective memory of the place, the nation, and the country. These collective memories maintain and strengthen the personal identity of the residents all the time (hometown, ethnicity, and nationality are all answers to the personal identity "who am I"). Collective memory can be associated with the perception of the landscape and the sense of identity at the same time, and play an intermediary role. Therefore, the following theoretical hypotheses are proposed:

H4: Collective memory has a mediating effect in the positive impact of landscape perception on residents' sense of identity.

\section{Research Area and Research Design}

\subsection{Study Area}

Yanbian city is located in the southeast of Jilin Province, adjacent to Russia and North Korea. It is one of the autonomous administrative regions of ethnic minorities in Chinese border areas and the only Chinese Korean autonomous prefecture in China. Yanbian prefecture is divided into 8 major counties and cities, of which Yanji City is the seat of the state government. The red revolution in Yanbian has a long history. As early as the winter of 1905, people from Korea who against Japanese imperialism were forced to exile in Yanbian city to develop against Japanese imperialism talents, which laid a valuable foundation for rich red cultural resources in this city. During the World War II, the War of Liberation in China, and the War to Resist US Aggression and Aid Korea for nearly 20 years, the great revolutionary martyrs, Communists party and the people of all ethnic groups fought battles without fear of difficulties. Therefore, Yanbian prefecture has a large number of martyrs' memorial facilities, battle sites and other revolutionary sites. According to statistics from domestic scholars and relevant government departments, among the 1,533 revolutionary sites distributed in Yanbian prefecture, among them, the number of martyrs' tombs, monuments (churches) and cemeteries is the most, with a total of 511. The registered martyrs of Yanbian area accounted for $41 \%$ of the total number of martyrs in Jilin Province, and more than $92 \%$ of the martyrs were Chinese Korean.

\subsection{Research Design}

The article data comes from the questionnaire. The first part of the questionnaire is the social demographic characteristics of the interviewee's gender, age, education level, and residence time etc. The second part borrows mature scales developed by the scholars, and divided into 3 subscales. Each subscale adopts a 5 point scale (Likert scale), and 1-5 values represents the degree of agreement of the interviewee with the item. Sculptures, memorials and monuments are all performance of the red cultural landscape. Combined with Yin (2015) and Si (2011)' research on sculptures, museums and other cultural landscapes, the Measurement Table for Residents' Perception of Red Cultural Landscapes in Yanbian Prefecture was compiled. There are 4 measurement items in this subscale. The Yanbian Prefecture Residents' Collective Memory Scale's 5 items was constructed with reference to the indicators proposed by Kong (2017) and Qian (2019). The 6 measurement indicators in the Measurement Table of Resident Status of Yanbian Prefecture are changed on the basis of the measurement items of place identity, ethnic identity, and ethnic identity compiled by Yang (2014), Phinney (1992), and Liu (2013).

\section{Data Collection and Processing}




\subsection{Data Collection}

The data is obtained in the form of field survey questionnaires. The survey process is divided into two survey stages: pre-survey (June 26-30, 2021) and formal survey (July 1 of the same year). Participants who answered the question "Are you a resident of Yanbian prefecture?" put forward by the writers were invited to fill in the questionnaire. A total of 243 valid questionnaires were obtained, and the questionnaire response rate reached $89.010 \%$. There were 100 male respondents and 147 female respondents. The ratio of male to female was $4: 6 ; 62 \%$ (151) of the respondents were between 18 and 45 years old; $47 \%$ (115) of the respondents were undergraduate and above, followed by $43 \%$ (105) with junior high school education; $61 \%$ of the respondents (148) said that they have lived in Yanbian area for 5 years or more.

\subsection{Data Processing}

First, using SPSS 22.0 to analyze the results of the questionnaire, test the reliability and validity of the questionnaire, determine whether the designed questionnaire can be factored, and delete some indicators with low load values. Secondly, the average value and standard deviation of the measurement items are used to describe the residents' perception characteristics of the landscape. Thirdly, using AMOS 24.0 to test the fit of the structural equation model, and then using SPSS 22.0 to test indicators such as path coefficients to determine the relationship between variables. Finally, the Model 4 script of the PROCESS macro program developed by Hayes was used to execute Bootstrap 5000 sampling times and set the confidence level to $95 \%$ to test the mediating effect of collective memory between the perception of the landscape and the sense of identity.

\section{Results and Analysis}

\subsection{Reliability and Validity Test}

The result of factor analysis showed that the KMO value of the scale was 0.846 , the significance index of Bartlett's spherical test was 0.000 , and the degree of explanation of the first factor for the entire scale was $23.049 \%(<40.0 \%)$, and there was no influence of common method deviation. Proving that the scale can be used for factor analysis. The Cronbach's alpha value is used to test the internal consistency of the scale. The higher the coefficient value, the better. After calculation, the Cronbach's alpha value of the total scale is 0.851 , and 3 subscale is higher than 0.700 , which proves the internal consistency of the scale is better. The AVE value and CR value can be used to test the scale's convergence validity. After analysis, the AVE value of the scale is close to or greater than 0.5 and the $C R$ value is greater than 0.7 , indicating that the scale the convergence validity of is more ideal. See Table 1 for specific values.

Table 1: Reliability and validity test results of each scale

\begin{tabular}{|c|c|c|c|c|}
\hline $\begin{array}{c}\text { Latent } \\
\text { variable }\end{array}$ & Specific indicators & $\begin{array}{l}\text { Cronbach's } \\
\text { alpha }\end{array}$ & AVE & $\mathrm{CR}$ \\
\hline \multirow{4}{*}{$\begin{array}{l}\text { Landscape } \\
\text { Perception }\end{array}$} & I think the color of the martyrs monument is majestic and beautiful. & \multirow{4}{*}{0.746} & \multirow{4}{*}{0.546} & \multirow{4}{*}{0.783} \\
\hline & I think the monument to the martyrs exaggerated the dignified and solemn atmosphere. & & & \\
\hline & I think the martyrs monument can show the revolutionary history and culture of Yanbian area. & & & \\
\hline & I think the monument is educational. & & & \\
\hline \multirow{5}{*}{$\begin{array}{c}\text { Collective } \\
\text { Memory }\end{array}$} & Through the monument to the martyrs, I was deeply impressed by the red culture of Yanbian prefecture. & \multirow{5}{*}{0.801} & \multirow{5}{*}{0.492} & \multirow{5}{*}{0.826} \\
\hline & Through the monument to the martyrs, I have a deeper feeling about the "harm caused by the invaders". & & & \\
\hline & The monument to the martyrs makes me imagine a scene where the people are in dire straits and in dire straits. & & & \\
\hline & The monument to the martyrs makes me imagine the scene of the martyrs fighting bravely. & & & \\
\hline & The monument to the martyrs can give me the enlightenment of "Don't forget the shame and cherish peace". & & & \\
\hline \multirow{6}{*}{ Identity } & I think the martyrs monument is the pride of Yanbian prefecture. & \multirow{6}{*}{0.793} & \multirow{6}{*}{0.597} & \multirow{6}{*}{0.855} \\
\hline & I am willing to protect the martyrs monument and other memorial facilities in Yanbian prefecture. & & & \\
\hline & When I see the commemorated martyrs of the same ethnic group, I am proud of our nationality. & & & \\
\hline & I am proud of my nationality and its revolutionary achievements today. & & & \\
\hline & I believe that the leadership of the Communist Party is great and correct. & & & \\
\hline & Chinese identity is very important to me. & & & \\
\hline
\end{tabular}

\subsection{Landscape Perception Characteristics}

Table 2: Residents' perception of the landscape

\begin{tabular}{|c|c|c|c|c|}
\hline $\begin{array}{c}\text { Question } \\
\text { item }\end{array}$ & Minimum & Maximum & Average & $\begin{array}{c}\text { Standard } \\
\text { Deviation }\end{array}$ \\
\hline 1 & 2.0 & 5.0 & 4.428 & 0.726 \\
\hline 2 & 3.0 & 5.0 & 4.630 & 0.619 \\
\hline 3 & 3.0 & 5.0 & 4.728 & 0.538 \\
\hline 4 & 2.0 & 5.0 & 4.770 & 0.534 \\
\hline
\end{tabular}

The results of the descriptive statistics show (Table 2) that the average scores of the first to fourth statements are all above 4.4 , indicating that the residents have a better perception of the landscape of the martyrs monument. However, the standard deviations of the respondents' recognition of statements 1 and 2 were higher than the latter two, indicating that residents' perception of the image of the martyrs monument is quite different. When communicating with residents, the author learned that students in Yanbian city have visited the martyrs monument many times under the organization of the school in recent years. An interviewee mentioned that "School took my daughter to visit martyrs monument, after she came back, she told us about her thoughts and feeling about the martyrs monument. I have been working for many years, I haven't touched it again. I don't know much about this aspect as my daughter." In addition, this result is related to the preservation status of the martyrs monument in Yanbian city. In recent years, the state government has remodeled the martyrs' monuments. Now most of the monuments in this area have been repaired (Figure 2 (b)), and there are monuments that maintain their old appearance (Figure 2 (a)). The monument before the restoration is different from the new monuments with uniform appearance and grandeur: Most of them were designed and built by the villagers spontaneously. The image difference of the monument affects the residents' perception of the appearance of the monument. The average value of t questions 3 and 4 is above 4.7 , and the standard deviation is small, indicating that residents have a high degree of recognition of 
the function of the monument, and the symbolic meaning "decoding" results are consistent.

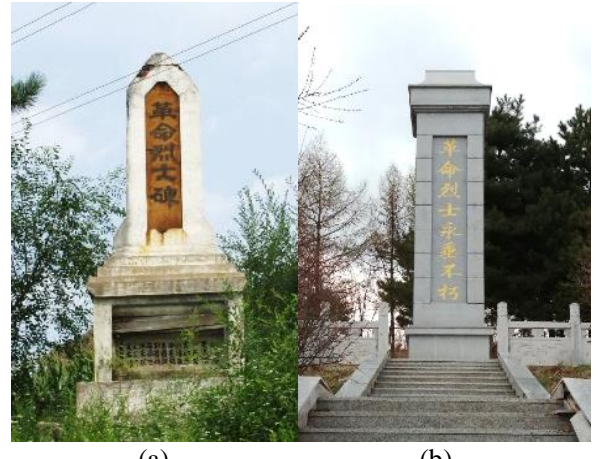

(a)

(b)

Figure 2: Old martyrs monument and new martyrs monument in Yanbian Prefecture

\subsection{Hypothesis testing}

Due to the poor fitting value of the initial model, the path between the two residual items in the same latent variable is added according to the covariance correction index MI (Modification Indices), and the optimal model is obtained after the initial model is revised. After analysis and testing by AMOS 24.0, the fit value of the revised model is as follows: $\mathrm{X}^{2} / \mathrm{df}=2.552<3.00, \quad \mathrm{GFI}=0.908>0.90, \quad \mathrm{IFI}=0.922>0.90$, $\mathrm{CFI}=0.921>0.90, \mathrm{SRMR}=0.071<0.080, \mathrm{RMSEA}=0.080$, the main index values are all within the acceptable range, and the revised structural simulation validity index is better. Using SPSS 22.0 to test the regression relationship between variables, the model test results show as Table 3. Landscape perception can positively affect collective memory $(\beta=0.588$, $\mathrm{p}<0.001)$ and identity $(\beta=0.437, \mathrm{p}<0.001)$. Collective memory has a significant positive effect on identity $(\beta=0.260$, $\mathrm{p}<0.001), 1-3$ hypothesis are all established.

Beginning in the 1940s, the government called on local governments to build buildings to commemorate the martyrs. People built monuments, memorial towers, and martyrs' cemeteries under the organization of local organizations such as village committees and township governments. Studies have shown that what kind of environmental cues influence what kind of collective memory people obtain. Martyrs' monuments (towers), paying homage to monuments, designing or reshaping monuments are the carriers and activities for the residents to recall/imagine the war years of the frontiers. Among them, the role of landscape symbols is the most prominent. The magnificent appearance, solemn atmosphere, and the dazzling and eye-catching inscriptions carry the people's respect and gratitude to the martyrs, and the meaning of teaching and expectation for future generations. The martyrs monument not only brings together memories such as the red memory, the memory of the World War II, and the memory of disasters, but the landscape itself also exists as the historical memory of Yanbian city. The monument has the characteristics of locality, nationality, and influence by power. Residents regard it as a symbol closely linked to their personal identity, which have a positive effect on strengthening residents' sense of identity and belonging.

As shown in Table 3, landscape perception and collective memory have a significant impact on place identity. After adding the intermediary variables, collective memory is used as the intermediary variable, and landscape perception and identity are respectively used as predictors and dependent variables. The influence of landscape perception (independent variable) on place identity (dependent variable) is still significant. Table 4 shows that the confidence interval of the path "landscape perception-identity" at the $95 \%$ confidence level is [0.068, 0.247], the interval does not contain 0 , the direct effect is significant, and the direct effect value is 0.172 $(\mathrm{P}<0.001)$, the effect accounted for $64.98 \%$. The $95 \%$ confidence interval of "landscape perception-collective memory-identity" is [0.045, 0.156], the upper and lower limits do not contain 0 , the mediating effect $(0.093)$ is significant, and the mediating effect accounts for $34.98 \%$. Therefore, the existence of collective memory as an intermediary variable in the perception of the landscape and identity can play a significant role (part of the intermediary role), hypothesis 4 holds.

Table 3: Hypothetical path result analysis

\begin{tabular}{|c|c|c|c|c|c|}
\hline & \multicolumn{2}{|c|}{ Significance of Regression Coefficient } & \multicolumn{2}{|c|}{ Global Fit Index } \\
\hline Predictor Variable & Outcome Variable & $\mathrm{T}$ & $\mathrm{B}$ & $\mathrm{R}^{2}$ & $\mathrm{~F}$ \\
\hline Landscape Perception & Collective Memory & 11.286 & $0.588^{* * *}$ & 0.346 & 127.374 \\
\hline Collective Memory & Identity & 3.730 & $0.260^{* * *}$ & 0.236 & 36.991 \\
\hline Landscape Perception & Identity & 7.551 & $0.437^{* * *}$ & 0.191 & 57.011 \\
\hline
\end{tabular}

Note: $* \mathrm{P}<0.05, * * \mathrm{P}<0.01, * * * \mathrm{P}<0.001$, the same below.

Table 4: Analysis of effect

\begin{tabular}{|c|c|c|c|c|c|c|}
\hline Relationship Test & Effect & Effect Value & Boot SE & Boot LLCI & Boot ULCI & Effect Ratio(\%) \\
\hline \multirow{3}{*}{ Landscape Perception-Identity } & Total Effect & $0.265^{* * *}$ & 0.054 & 0.164 & 0.378 & 100 \\
\cline { 2 - 7 } & Direct Effect & $0.172^{* * *}$ & 0.045 & 0.068 & 0.247 & 64.98 \\
\cline { 2 - 7 } & Mediation Effect & $0.093^{* * *}$ & 0.028 & 0.045 & 0.156 & 34.98 \\
\hline
\end{tabular}

New cultural geography believes that from the perspective of representation, culture and power are the productive forces of the landscape, and both "code" the cultural landscape together, and the monument is the product of society. In other words, the monument is a metaphor for politics, culture, economy and control. Individuals interpret the product (landscape) under a specific cultural and power background based on their own background and experience. The landscape has different meanings due to the identity of the interpreter. The members with common memories and emotions are the "us", in their eyes: the monument symbolizes the people's masters of the country, patriotism, and socialist ideas. It commemorates the hometown heroes, the fighting heroes of their nationality, and the patriotic soldiers who gave their lives for China. From a non-representational point of view, although the martyrs are not there, the material landscape closely connected with heroes and history, fills the gaps in memory. Places, landscapes and other memory places condense the collective memory of residents, the latter promotes residents to generate local pride, ethnical pride, national pride, etc., as well as protecting monuments, actively learning national heroes, supporting national sovereignty and other abstract attitudes 
and emotions and actions. This explains the hypothesis that collective memory can play a mediating effect in the process of landscape perception affecting identity.

\section{Conclusion and Discussion}

\subsection{Conclusion}

Based on the perspective of emotion and landscape research in New Cultural Geography, this paper establishes the theoretical framework of "landscape perception-collective memory-identity", and uses empirical research to confirm the hypothesis. The results show that: a. Residents have a higher perception of the monument landscape, but their image perception is different. b. Landscape perception can directly positively affect identity, and it can also have a significant positive impact on collective memory. c. The construction and restoration of collective memory helps residents construct or strengthen their sense of identity. d. The red cultural landscape is conducive to the formation of common memory, and further strengthens identity through the intermediary effect of collective memory.

\subsection{Problems}

Since identity does not have a unified conceptual definition and dimensional division, based on the research purpose and object, the article selects three kinds of identity to form the identity discussed in this article, the place identity of Yanbian area and the identity of ethnic groups and a sense of identity with the country. In the future, multi-dimensional identity should be introduced into the research framework to improve the scientificalness of the theory. The data obtained is extremely closely related to the socio-demographic characteristics of the survey subjects. The respondents in the survey are mostly young people, people with high education levels, and female residents. Besides the survey is only conducted in Yanbian city. The reliability and accuracy of the data are affected to a certain extent. Subsequent research should expand the object group, expand the study area, complicate the questionnaire.

\subsection{Practical Inspiration}

The analysis results of the intermediary effect have guiding and reference value for the practical work: a. In the process of designing and reshaping the red cultural landscape in the future, we should avoid repeated construction through brainstorming. b. Landscape is the product of culture, and protecting the red cultural landscape is to respect and inherit the red culture. It is necessary to pay attention to the compilation and statistics of the red cultural landscape, and use big data and geographic information technology software to integrate the red cultural resources. c. In the process of surveying, the author found that some residents never see seen the monument. As a way to connect the masses and the red cultural landscape, red tourism could activated and used the local red cultural symbols. In this way can we cherish the memory of the martyrs, learn the heroic spirits, better remember the revolutionary history of the heroes protecting the family and the people

\section{Acknowledgements}

We would like to thank The National Natural Science Foundation of China for "Research on the Distribution Characteristics and Evolution of Cultural Landscapes of Place Names in the Changbai Mountains" (41761027) and The Yanbian University Social Science Fund entrusted the project "Yanbian Historical and Cultural Geographical Resources Database Construction" (602021107), and these two projects funded this article.

\section{References}

[1] Alice M.: Memory, Uncertainty and Industrial Ruination: Walker Riverside, Newcastle upon Tyne, International Journal of Urban and Regional Research, 2010, 34: 398-413.

[2] Cloke P. et al. Introduction to Human Geography, Taipei: Juliu Book Company, 2006, 75: 230-231.

[3] De Blij, Harm J, Muller Peter O. Human Geography: Culture, Society and Space 3rd ed. New York: John Wiley and Sons, 1986, 142.

[4] Drozdzewski D. Using history in the streetscape to affirm geopolitics of memory, Political Geography, 2014, 42: 66-78.

[5] Du L X. A Study on National ldentity of College Students, Zhejiang University, 2014.

[6] Hur W M.et al. How CSR Leads to Corporate Brand Equity: Mediating Mechanisms of Corporate Brand Credibility and Reputation, Journal of Business Ethics, 2014, 125: 75-86.

[7] Kong X, Zhuo F Y. Roles of Cultural Landscapes in the Construction of Local Collective Memory: A Case Study of Chengkan Village, Scientia Geographica Sinica, 2017, 37: 110-117.

[8] Li D L. Symbols, Collective Memory and National Identity, Dushu, 2001: 104-107.

[9] Li F.et al. A Geographical Study on the Collective Memory of Urban Historical Cultural Landscape, Human Geography, 2010, 25: 60-66.

[10] Li X J. Literature Review of Collective Memory Research, Journal of Shanghai Educational Research, 2009(4): 8-10.

[11] Liu H H. College Students' Party Identity and National Identity-Based on the Empirical Research of Beijing Universities, Marxism \& Reality, 2013: 85-92.

[12] Liu M, Guo R T. Research on Historical Memories, Signs in Landscape and Construction of Ethnic Identity-Based on the Investigation into the Landscape Semiotics of the Gelao Villages in Guizhou, Journal of Guangxi University for Nationalities (Philosophy and Social Science Edition), 2021, 43: 108-116.

[13] Liu Y X. The Red Memorial Landscape Narratives and its Influences on National Identity: A Case Study of Gelesh an Martyrs Memorial Park in Chongqing City, Chengdu University of Technology. 2019.

[14] Maurice Halbwachs, Guo J H. On Collective Memory, Shanghai: Shanghai People's Publishing House, 2002, 37-41.

[15] Phinney J S. The Multigroup Ethnic Identity Measure: a New Scale for Use with Adolescents and Young Adults from Diverse Groups, Journal of Adolescent Research, 1992, 7: 156-176. 
[16] Phinney J S. Ethnic Identity in Adolescents and Adults: Review of Research, Psychological Bulletin, 1990, 108: 499-514.

[17] Qi J, Tang X Q. Viewing the Production of Traditional Settlement Landscape in Ethnic Tourist Destinations from the Triple Meaning of Landscape Identity, Tourism Tribune, 2020, 35: 3-5.

[18] Qian L L.et al. The Relationships among Post-disaster Collective Memory, Place Identity and Place Protection Intention of Local Residents: A Case Study of Wenchuan Earthquake Ruined Town of Beichuan, Geographical Research, 2019, 38(4): 988-1002.

[19] Qian L L.et al. The Construction of Collective Memory of Dark Tourism Sites and its Influence on Tourists' Behavioral Intentions: A Case Study of the Earthquake-stricken Old Town of Beichuan County, Tourism and Hospitality Prospects, 2020, 4: 59-74.

[20] Si L N, Tan J. Correlation Analysis on The Perceived Image of Museum-A Case Study of Capital Museum, Yunnan Geographic Environment Research, 2011, 23: 13-18.

[21] Stedman R, Beckley T, Wall Ace S, et al. A Picture and 1000 Words: Using Resident-Employed Photography to Understand Attachment to High Amenity Places, Journal of Leisure Research, 2004, 36: 580-606.

[22] Sun J X, Zhou Y. Residents' Place Identity at Heritage Sites: Symbols, Memories and Space of the "Home of Diaolou", Geographical Research, 2015, 34: 2381-2394.

[23] Tang M L. The Inventory and Progress of Cultural Landscape Study, Progress in Geography, 2000: 70-79.

[24] Wheeler, Rebecca. Mining memories in a rural community: Landscape, temporality and place identity, Journal of Rural Studies, 2014, 36: 22-32.

[25] Xu H, Zhou Z K. The Research on the Influence Mechanism of Smellscape Perception on Rural Place Attachment: An Analysis of the Mediating Role of Nostalgia, Human Geography, 2020, 35: 48-55.

[26] Yang L. Research on the Protection and Utilization of the Red Cultural Landscape in Guangzhou under the Background of Red Tourism, South China University of Technology, 2013.

[27] Yang L G.et al. On Perception and Identification of Traditonal Settlements' Landscape Genes in Chinese Minority Areas: A Case Study in Taro Dong Minority Village of Tongdao, Human Geography, 2014, 29: 60-66.

[28] Yin D. Effect of the Meaning of Urban Sculpture Landscape on Residents and Tourists' Sense of Place to Urban Tourism Destination, Inner Mongolia University, 2015.

[29] Yin S.et al. Mountain Type Ethnic Village Residents under the Background of Tourism Development-Take Leigong Mountain Area in Guizhou as an Example, World Regional Studies, 2021: 1-18.

[30] Zhang Y. Media. Geography and Identity: Forming and Changing of the National Identity in Southwest Minorities, Zhejiang University, 2014.

[31] Zhu H, Liu B. Concepts Analysis and Research Implications: Sense of Place, Place Attachment and Place Identity, Journal of South China Normal University (Natural Science Edition), 2011: 1-8.

\section{Author Profile}

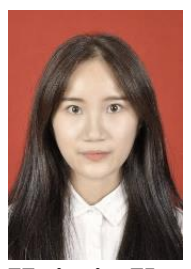

Huimin $\mathrm{Xu}$ received a double degree in tourism management and English from Shandong First Medical University in 2016. Since 2020, she has entered the College of Geography and Ocean Sciences of Yanbian University to study for a master's degree in geography. The main research direction is sociocultural geography. 